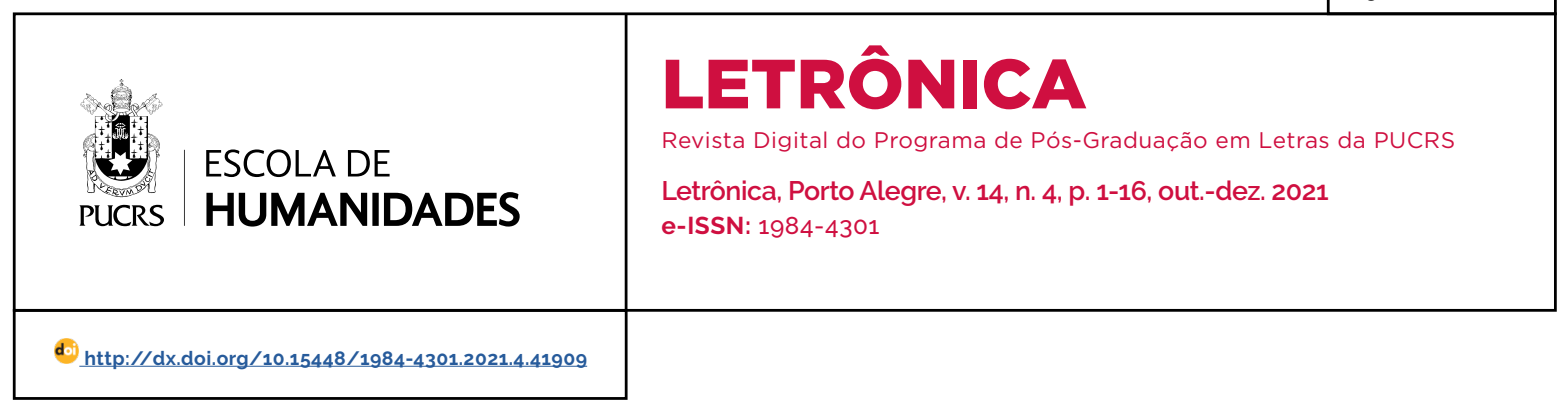

SEÇÃO: ARTIGOS

\title{
COVID-19 e o reflexo dos indícios discursivos de fratura social no Brasil
}

\author{
COVID-19 and the reflection of discursive evidence of social fracture in Brazil
}

\section{Liz Feré ${ }^{1}$ \\ orcid.org/0000-0001-9210-4568 \\ info@lizfere.com}

Recebido em: 03/10/2021 Aprovado em: 29/11/2021. Publicado em: 27/01/2022.
Resumo: Este artigo tem como proposta uma reflexão sobre a estrutura simbólica da divisão de classes e o poder da linguagem nas relações sociais no Brasil. Para responder à problemática desta pesquisa, analisaremos as condições de trabalho dos profissionais da área de recicláveis, sob as perspectivas teóricas de Bourdieu e Bakhtin em diálogo com Maingueneau. Os discursos selecionados são da escritora e poeta Carolina Maria de Jesus, de sua obra "Quarto de despejo", de 1950, em contraste com discursos atuais de Anne Caroline, catadora de recicláveis, em São Paulo.

Palavras-chave: Aforização. Relações de poder. Reciclagem. Discurso.

Abstract: This article focusses a reflection on the symbolic structure of class division and the power of language in social relations in Brazil. To answer the problem of this research, we will analyze the working conditions of professionals in the recyclable area, under the theoretical perspectives of Bourdieu and Bakhtin in dialogue with Maingueneau. The selected speeches are by the writer and poet Carolina Maria de Jesus, from her work "Quarto de despejo", from 1950 in contrast to current speeches by Anne Caroline, recyclable waste picker, in São Paulo.

Keywords: Aphorization. Recyclable professionals. Unequal power relations. Language.

\section{Introdução}

Os últimos meses de 2019 e o ano de 2021 foram marcados pela pandemia da COVID-19, que intensificou a crise econômica e social que há anos assola o mundo inteiro e potencializou as dificuldades de natureza política, social, econômica, mas também aquelas ligadas às relações interpessoais. É sabido que uma crise pandêmica, se associada a altos niveis de violência, desemprego, destruição ambiental e social, expande-se em quase todas as camadas da sociedade. Evidentemente, os que mais sofrem com a falta de oportunidades, com o desrespeito e, sobretudo, com a precariedade são os cidadãos de baixa (ou nenhuma) renda. No Brasil não é diferente.

\section{(c) (1)}

Artigo está licenciado sob forma de uma licença Creative Commons Atribuição 4.0 Internacional.

\footnotetext{
Université Paris VIII, Centre d'Études sur les Médias, les Technologies et l'internationalisation, Paris, França.
} 
A pandemia chegou potencializando problemas de todas as ordens, sobretudo sociais.

Na tentativa de conter a propagação do vírus, a contar do mês de março de 2020, foi dado início ao isolamento² social. A maior parte das autoridades mundiais optaram pelo autorrecolhimento dos cidadãos às suas residências.

A partir daquele momento, o enunciado " $f$ que em casa", precedido do sinal topográfico da "cerquilha" (hashtag), viralizou nas redes sociais. Entretanto, revelou uma imensa fratura social, na medida em que o isolamento se aplica ao cotidiano daqueles que têm o privilégio de trabalhar em casa, via Internet. Esta parcela privilegiada da sociedade adaptou sua rotina ao chamado "teletrabalho" e às reuniões on-line como forma de compensar o distanciamento social.

O problema é que grande parte dos cidadãos brasileiros não tem acesso nem mesmo aos serviços básicos, como água potável e saneamento. ${ }^{3}$ Para estas camadas mais pobres da população, que precisam trabalhar durante o dia para trazer sustento à noite, só lhes resta aceitar as "condições" do trabalho informal (sem vínculos e direitos trabalhistas), como é o exemplo dos trabalhadores que catam materiais recicláveis.

Retomando as palavras de Charaudeau (2009), a problemática de uma investigação, sendo definida por meio de hipóteses de representações sociodiscursivas, leva em conta um momento da história de uma determinada sociedade, e caracterizam tal ou tal grupo social. Nossa problemática concentra-se na influência da linguagem nas relações sociais dentro de uma sociedade hierarquizada com uma rígida estrutura de poder simbólico pautado na divisão de classes. É a partir de preceitos teóricos, sob a luz das teorias sociais de Bourdieu em diálogo com a filosofia da linguagem, como a entende Bakhtin, que propomos uma reflexão sobre as estruturas de poder simbólico que regem o país, fazendo com que grande número de brasileiros sejam relegados às margens da sociedade, e de como esta última "normaliza" tal condição. Os discursos analisados serão da escritora e catadora Carolina Maria de Jesus, selecionados no seu livro Quarto de despejo, escrito em 1950, em contraste com os discursos de Anne Caroline, catadora de material reciclável, cuja fonte foi uma entrevista (live) pela rede social Instagram, no dia 3 de novembro de 2020.

A abordagem do objeto de nosso tema de estudo faz-se a partir da formulação de hipóteses sobre as estruturas de poder simbólico, a fratura social e suas interações no domínio discursivo.

Dentro deste contexto, propomos como escopos: a) promover o debate sobre as estruturas de poder simbólico que atuam na sociedade e que perpassam os discursos da vida cotidiana brasileira; b) discorrer sobre as questões da construção de sentido através das relações dialógicas dos enunciados; c) refletir sobre as produções de sentidos segundo a posição social do sujeito, bem como as mudanças ocorridas entre meados de 1950 e para o contexto pandêmico de 2021, no que diz respeito à condição de vida (ou de sobrevivência) dos catadores de recicláveis, moradores das favelas, exemplificadas aqui pelos discursos de duas catadoras, ambas do estado de São Paulo.

A estrutura deste artigo é a seguinte: a) um panorama do contexto brasileiro, especificamente o caso dos profissionais da área de recicláveis, que será embasado nas teorias de Bourdieu em breve diálogo com outros autores, tais com Goffmann, Marx, Weber, Durkheim, Charaudeau e Foucault; b) a abordagem teórica sobre a construção de discursos, com ênfase nas teorias do Círculo de Bakhtin, como a do dialogismo, bem como a da valoração e da designação; mencionaremos a noção de enunciados aforizantes, analisados pela perspectiva teórica de Maingueneau; c) posteriormente, apresentaremos a metodologia e o corpus utilizados, o segundo construído com base nas propostas de Charaudeau, com enfoque nas variáveis de um mesmo contrato comunicacional em diferentes épocas, constituidos pelo discurso da escritora e catadora Carolina Maria de Jesus, durante os anos 1950, e pelo discurso de 
Anne Caroline, em novembro de 2020, catadora de material reciclável, nas ruas de São Paulo; e d), considerações finais.

\section{O contexto brasileiro entre poder real e simbólico}

No panorama mundial, que precede a crise pandêmica, a condição imposta aos individuos sempre foi desigual. E a crise sanitária intensificou esse desequilibrio social, na maior parte dos países do mundo. Sobre esta questão, retomamos as palavras de Baumann (2007), ao mencionar o estudo de Jacques Attali (2004), ${ }^{4}$ sobre o fato de que metade do comércio mundial - sobretudo uma grande parte do investimento global - beneficia somente 22 paises que comportam apenas $14 \%$ da população mundial, ao passo que 49 países mais pobres recebem apenas 0,5\% do produto global. Este valor pode ser comparado com a renda combinada de apenas três dos homens mais ricos do mundo. Isso porque:

Noventa por cento da riqueza total do planeta estão nas mãos de apenas $1 \%$ de seus habitantes. E não há quebra-mares à vista capazes de deter a maré global da polarização da renda que continua aumentando de maneira ameaçadora (BAUMAN, 2007, p. 12).

Do ponto de vista brasileiro, alguns elementos históricos compõem as particularidades deste contexto, principalmente sua fragmentação e as desigualdades abismais. Dentre eles, citemos a sua Independência, que foi mais uma revolta fiscal do que uma independência propriamente dita, fez-se sem que houvesse uma verdadeira descolonização. Assim sendo, foram os colonizadores estabelecidos no país que tomaram o poder e criaram uma colônia autocentrada. De modo geral, as independências dos países americanos ocorreram sem descolonização, os quais tornaram-se Estados coloniais, mas "o caso brasileiro é extremo, pois a independência foi proclamada pelo herdeiro do trono do pais colonizador",5 para retomar as palavras de Michel Cahen (2019). ${ }^{6}$

Em vista do mencionado, mais flagrante ainda é o fato de que as classes dominantes brasileiras mantiveram-se presas a esse modelo e apegadas aos padrões das relações entre "senhores" e "escravos". Aos poucos estas classes dominantes tornaram-se uma burguesia mais financeira do que industrial, mas conservando em grande parte sua caracteristica latifundiária. A relação das classes dominantes com o povo não é apenas uma relação de capitalista a proletário, mas ainda em grande parte uma relação de senhor(a) da "Casa Grande" a escravo(a) da "Senzala". Assim sendo, as classes dominantes exercem seu poder com base na humilhação cotidiana, seja explícita ou implícita, para manter os "subalternos" em "seus devidos lugares".

Quanto aos aspectos econômicos, convém lembrar que, no Brasil, antigamente, as classes sociais estavam oficialmente designadas em A (os ricos, a camada da população que recebia mais de 20 salários mínimos ${ }^{7}$ mensais), B (as chamadas classes médias, os que recebiam de 10 a 20 salários mínimos (SM) e C (classe baixa, aqueles que não recebiam nenhum salário ou que ganhavam até 10 salários mínimos (SM).

Nos anos 2000, um estudo feito pela Fundação Getúlio Vargas (FGV), dirigido pelo economista Marcelo Neri, demonstrou que essa classificação era tão arbitrária quanto insuficiente para explicar como um individuo poderia ganhar até mais de mil vezes o que ganhava outro. Para tentar traduzir mais finamente a realidade, foram acrescentadas, com base na renda, as classes D e E. A classe D é constituída por aqueles cuja renda mensal vai de R\$ 751,00 até o limite da classe C e a classe E é composta dos mais precários, ou seja, aqueles cuja renda é nula ou não atinge $\mathrm{R} \$ 751,00 .^{8}$

\footnotetext{
4 ATTALI Jacques. La voie humaine. Paris: Ed. Fayard, 2004

LE RETOUR du Brésil colonial. Libération, [S. I.], 2 jul. 2019. Disponivel em: https://www.liberation.fr/debats/2019/07/02/le-retour-du-bresil-colonial_1737589. Acesso em: 2 nov. 2020.

6 Michel Cahen é professor e historiador da colonização portuguesa, pertence ao laboratório de pesquisa do CNRS da Sciences PO de Bordeaux

7 Salário mínimo (SM) no Brasil, hoje - R\$ 1.045,00. Disponivel em: https://www.in.gov.br/web/dou/-/medida-provisoria-n-919-de-30-de-janeiro-de-2020-240824899. Acesso em: 27 dez. 2021.

8 Esses valores correspondem ao ano de 2019, quando o salário minimo era de R\$ 998,00. Disponivel em: http://www.guiatrabalhista. com.br/guia/salario_minimo.htm. Acesso em: 24 mar. 2021.
} 
De acordo com o sociólogo Jessé Souza (2016), somente $20 \%$ da população brasileira é realmente privilegiada. Destes 20\%, apenas 2\% constituem a chamada "elite" - aquela que dispõe, sobretudo, de capital econômico - os outros 18\% deste grupo formam a "massa" da elite, que seria a chamada "classe média alta". Estes 20\% detêm as rédeas da sociedade.

Os 80\% "restantes" situam-se nos mais variados niveis da classe trabalhadora e incluem também as camadas precárias. Abaixo de todas elas, está o grupo que Jessé Souza (2016) chamou de "ralé", que corresponde às classes D e E. A "ralé" é composta pelos excluídos, pela massa destinada ao trabalho braçal e para a qual quase todas as oportunidades de crescimento são inacessiveis.

De forma geral, as dificuldades enfrentadas por uma criança da "ralé" serão incalculáveis. Ela chegará à escola sem nenhum preparo emocional e muitas vezes mal (ou não) alimentada, sem condições de prestar atenção na aula, de seguir o conteúdo por falta dos requisitos básicos para isso. Todos esses fatores resultarão na incapacidade dessa criança de tornar-se um adulto "competitivo" e habilitado a responder às rígidas demandas do mercado de trabalho e da vida social.

A grande maioria das pessoas que formam as classes precárias e a "ralé" são negras e pardas, ${ }^{10}$ bem como mais de 72\% (MEIRELLES; ATHAYDE, 2014) dos habitantes de favelas e periferias também são negros e pardos. A discriminação racial é um dos pontos centrais da desigualdade e da injustiça social no Brasil.

Dentro dessa conjuntura, pode-se dizer que a construção e reprodução de estereótipos discriminatórios resultam de um processo de objetivação, no qual a pessoa, quanto mais escura for a cor da sua pele, mais será estigmatizada.

Abrimos um parêntese para uma breve abordagem sobre a questão racial, haja vista sua influência predominantemente devastadora no cenário mundial e brasileiro.
É fato que o racismo é uma consequência bem real de uma "teoria" fundamentada no pressuposto errôneo da existência de "raças" humanas e na escolha ideológica de hierarquizá-las. As especificidades psicológicas dos indivíduos têm pouca importância no processo que estrutura a noção de racismo. Este traduz-se em expressão simbólica e cultural de uma sociedade organizada e historicamente hierarquizada em torno da dominação exercida por um grupo social sobre outro (TAGUIEFF, 2013).

1888 foi o ano que marcou o fim oficial da escravidão no Brasil. Mas, desde então, as atrocidades nunca acabaram. As desigualdades, injustiças e humilhações não diminuiram com o fim da escravidão (FAUSTO, 2007). Os europeus que imigraram ao país sempre foram avantajados em relação aos ex-escravos, para os quais restavam os trabalhos mais precários e com rendas inferiores, tais como engraxates, varredores ambulantes, quitandeiras, catadores etc.

No Brasil, de acordo com Silvio Almeida (2019), o racismo é estrutural e é construido de tal forma que constitui a base das relações sociais e tido como padrão de "normalidade", sendo uma forma de compreensão das relações interpessoais. No que tange ao que é "normal" ou não, para Michel Foucault (1979) a normalidade pressupõe relações de poder, um poder que classifica, controla e decide o que é normal em cada momento da história, condenando e punindo todos aqueles que não se enquadram na dita "norma". No Brasil, a normalidade exclui e estigmatiza os pobres, os idosos, as mulheres (quanto aos dois últimos, há controvérsias; pois ainda que sofram discriminações pelo gênero ou pela idade, eles mantêm seus privilégios caso pertençam a uma classe social superior), os LGBTQIA+, os deficientes, os que não se adequam aos rigidos padrões de beleza e tantas outras categorias.

A associação destes e tantos outros elementos formam a cadeia da desigualdade e da vulnerabilidade social, sobretudo no que diz respeito 
às mulheres negras, muitas das quais são responsáveis sozinhas pelo sustento do lar, como era o caso da escritora Carolina Maria de Jesus.

Os catadores, por sua vez, desempenham um importante papel na preservação da natureza, mas isso não se traduz nas condições de trabalho. Esses profissionais ocupam posições nas bases da escala social, em situações de vida precárias e, na maioria dos casos, indignas. E é por esta razão que focalizaremos nosso estudo sobre esses profissionais.

\section{Vozes invisibilizadas}

Prosseguimos, então, com a reflexão sobre as condições dos profissionais da área de recicláveis que, segundo o Instituto de Pesquisa Econômica Aplicada (IPEA), só no Brasil, 90\% do material reciclado é recolhido por catadores, o que corresponde a mais de 800 mil profissionais da área em todo o país. Esses cidadãos brasileiros são aqueles que poderiam ser considerados como uma subcategoria da "ralé", dadas as condições de precariedade e desdém a que são submetida(o)s.

A precariedade que enfrentam os catadores sempre se fez presente, e a estes profissionais não se aplica a possibilidade de ficar em casa, menos ainda de trabalhar à distância. Isto porque, historicamente, a atividade de catador(a) de recicláveis é realizada de maneira informal e, na maioria dos casos, estes trabalhadores não são registrados oficialmente. Esta "informalidade" os coloca em condições de extrema vulnerabilidade econômica e é por esta razão que grande parte destes profissionais sobrevivem nas ruas ou moram em barracos insalubres nas periferias e em favelas das grandes e médias cidades do país. Só na cidade de São Paulo, o número das pessoas em situação de rua aumentou mais de
$53 \%{ }^{11}$ no último ano. Nesse contexto pandêmico, o volume de residuos domésticos aumentou de 15\% para $25 \% .{ }^{12}$ Segundo a Associação Brasileira de Empresas de Limpeza Pública e Residuos Especiais (Abrelpe), uma única residência produzia aproximadamente 4,86 kg de lixo semanais; esse número subiu para $5,83 \mathrm{~kg}$ depois da pandemia da COVID-19. Esse aumento está associado a uma procura por produtos de uso único. No entanto, esse aumento, além de não beneficiar os catadores de recicláveis, só piorou a situação. Mais de $80 \%$ das organizações de catadores ficaram paralisadas devido às dificeis condições de trabalho e ao forte risco de contágio a que são expostos. Segundo a pesquisadora Fernanda Lira, do IPEA,13 "A maior parte dos trabalhadores está em situação de fragilidade, sem registro formal e sem nenhum tipo de proteção trabalhista ou do poder público" Além da precariedade, a maior dificuldade que se apresenta a eles é o preconceito e a discriminação. Como relata este catador da cidade de São Paulo: "Acham que tudo é lixo, que a gente é lixo. Mas na verdade isso aqui [apontando para a carroça cheia] é mercadoria, e o que estamos fazendo é ajudar a limpar a cidade", diz João. ${ }^{14}$

Fazemos aqui uma primeira ressalva no que diz respeito à denominação desta atividade profissional e preferimos dizer catadores de recicláveis e não catadores de lixo, pois o termo "lixo" não é adequado a este tipo de atividade, na medida em que a palavra carrega conotações fortemente negativas. Deve-se mencionar, também, que, semanticamente, "lixo" só é aplicável por quem o descarta. De acordo com a pesquisadora Magalhães (2012, p. 44): "Para as pessoas que recolhem o material e the dão um destino diferente do descarte, o termo "lixo", no estrito sentido do

\footnotetext{
11 Mais informações sobre dados relativos a pessoas sem teto nas ruas da cidade de São Paulo disponiveis em: https://www1.folha. uol.com.br/poder/2020/10/alta-de-moradores-de-rua-apos-pandemia-exigira-resposta-de-prefeito-de-sp-em-diversas-areas.shtml. Acesso em: 24 out. 2020.

12 BISPO, Daisy; AMORIN, Davi. Catadores de materiais recicláveis: a linha de frente invisivel. Le monde diplomatique Brasil, 11 de dez. 2020. Disponivel em: https://diplomatique.org.br/catadores-de-materiais-reciclaveis-a-linha-de-frente-invisivel/?fbclid=IwAR2wa6z4Y2HWgn2uDTntTpxJv5rmxCD7mvImo02B5QBbyKd3qsNCogZxgml. Acesso em: 25 nov. 2020.

13 IPEA - INSTITUTO DE PESQUISA ECONÔMICA APLICADA. Pesquisa sobre pagamento por serviços ambientais urbanos para gestão de resíduos sólidos. Brasília: Ipea, 2013; Diagnóstico sobre os catadores de resíduos sólidos. Brasília: Ipea, 2013. Disponivel em : https:// www.ipea.gov.br/portal/images/stories/PDFs/situacao_social/131219_relatorio_situacaosocial_mat_reciclavel_brasil.pdf. Acesso em : 20 nov. 2020

14 MORI, Leticia. Acham que a gente é lixo: a rede invisivel de catadores que processa tudo o que é reciclado em SP. BBC Brasil, 20 jul. 2017. Disponivel em: https://www.bbc.com/portuguese/brasil-40664406. Acesso em: 25 nov. 2020.
} 
termo, não é correto, já que se trata precisamente do material que será aproveitado para lhes prover o sustento". E é por intermédio da atividade dos catadores que será transformado esse material, o lixo (inútil), em mercadoria (dotada de valor de uso e de troca). A reinserção desses materiais em mercadorias reaproveitáveis e sua recolocação no ciclo produtivo gerarão vantagens positivas tanto para a natureza quanto para a sociedade (MAGALHÃES, 2012, p. 44).

Uma segunda ressalva deve ser feita para salientar a dificuldade ainda maior que é enfrentada, neste caso, pelos catadores e catadoras negras, que é o preconceito racial presente no cotidiano destes trabalhadores. Nesse contexto, cabe uma menção à construção do sentido que é dada à noção de preconceito: trata-se do juízo baseado em estereótipos sobre individuos que pertençam a um determinado grupo racializado, resultando ou não em discriminações. Já a discriminação que sofrem esses (e muitos outros) profissionais negros diz respeito à atribuição de um tratamento diferenciado a pessoas pela cor da pele. Acrescenta-se a isso o estigma ligado à situação de vulnerabilidade social destes profissionais (ALMEIDA, 2019, p. 32).

O resultado dessa equação é a discriminação direta sofrida por ela(e)s, no repúdio manifesto a indivíduos ou grupos, motivado pela condição racial e social.

\section{Referencial teórico}

A questão das relações sociais deve ser analisada para além do aspecto econômico, sob o ângulo da reprodução de privilégios, relacionada com o que Bourdieu nomeou de capital simbólico, que nada mais é do que os resultados da acumulação de privilégios e de recursos simbólicos por um grupo de individuos. Vejamos como Weber, Durkheim e Bourdieu podem esclarecer-nos sobre essa questão das relações sociais.

Para Max Weber (2003), o individuo é inerente à sociedade e as suas ações definem as estruturas da sociedade. Já para Émile Durkheim (2007) a sociedade é uma organização constituida, e o autor busca entender como as estruturas deter- minam os comportamentos dos indivíduos. De acordo com essa visão, a sociedade transcende o indivíduo, uma vez que independe dele. Em todo caso, não há sociedade sem estrutura social, e todos os niveis deste sistema são representados por relações de poder simbólico.

Pierre Bourdieu (2002) articula os pensamentos de Weber e Durkheim, afirmando que tanto o meio social constitui o indivíduo quanto é construido por ele, e considera as relações individuais ou coletivas como a base da realidade social. Para Bourdieu, não se trata de simples relações entre indivíduos ou grupos, mas sim de redes de laços, quer sejam materiais ou simbólicas. Para ele, estas relações manifestam-se de duas formas principais:

\begin{abstract}
Primeiramente, "reificadas como conjuntos de posições objetivas que as pessoas ocupam (instituições ou "campos") e que, externamente, determinam a percepção e a ação; e, a segun$\mathrm{da}$, diz respeito às que foram internalizadas na forma de esquemas mentais de percepção e apreciação (cuja articulação, em camadas, compõe o "habitus"), através dos quais experimentamos internamente e construímos ativamente o mundo em que vivemos" (BOURDIEU, 1980, p. 29).
\end{abstract}

A noção bourdiesiana de capital nos permitirá entender as bases que regem as formas de poder simbólico na sociedade brasileira. Como mencionamos, o capital simbólico não se restringe apenas ao capital econômico, amplamente analisado por Karl Marx. Segundo Bourdieu (1982), é possivel distinguir três outros tipos de capital: o capital cultural (ligado ao conhecimento e ao saber), o capital social (constituido pelos contatos e relacionamentos) e, por fim, o capital simbólico (relacionado com a imagem de si, o status etc.). Esses capitais podem atuar de forma independente ou completarem-se. Importa ressaltar que as desigualdades geradoras dessa triade de capitais são incomensuráveis para os que se encontram na base da pirâmide social.

No que diz respeito aos conceitos linguísticos, Bourdieu (1982) os submeteu a um triplo deslocamento: a) da noção de linguagem, pela noção de linguagem legítima; b) de relações de comunicação às relações simbólicas de poder; e 
c) da questão do significado da palavra, à questão do valor e do poder da palavra. E para ele, quanto mais uma sociedade é hierarquizada, mais a palavra é codificada, sabendo-se que a ação da linguagem não deve ser dissociada de suas condições sociais de produção. Corrobora, assim, com a teoria da linguagem, especialmente a de Mikhail Bakhtin (2017), para quem o uso da linguagem deve levar em conta os seus contextos específicos, em relação com as estratificações sociais especificas, sendo impossivel pensar o social desvinculado do sujeito.

Observemos que a interação verbal, indissociável das outras formas de interação, acarreta conflitos, relações de dominação e de resistência, aceitação, de submissão ou de resistência à hierarquia, além do uso da língua pela classe dominante para reforçar seu poder.

A convivência entre os sujeitos é carregada de conflitos, pois se dá sob uma forte relação de dominação que, segundo Bourdieu (1982), diz respeito à relação entre individuos que ocupam diferentes posições no espaço social: os dominantes e os dominados.

Para melhor entender a expressão "classe dominante" no contexto brasileiro e a fratura existente entre uma minoria rica e uma maioria pobre, é necessário observar o conceito de estigma a partir da proposta de Goffmann (1981, p. 8-9):

Construímos uma teoria do estigma; uma ideologia para explicar a sua inferioridade e dar conta do perigo que ela representa, racionalizando algumas vezes uma animosidade baseada em outras diferenças, tais como as de classe social. Utilizamos termos especificos de estigma como aleijado, bastardo, retardado, em nosso discurso diário como fonte de metáfora e representação, de maneira caracteristica, sem pensar no seu significado original.

Assim como existe uma forte discriminação racial no Brasil, a discriminação por classes (estigma da pobreza) é igualmente nefasta e uma sobrepõe-se à outra.
Podemos observar no capitulo anterior, no relato do catador João: "Acham que somos lixo", é o estigma construido por uma minoria privilegiada que dito repetidas vezes constrói (destrói, neste caso) os imaginários sociais dos indivíduos na sua condição de ser social.

Os discursos pré-concebidos que circulam no espaço público servem de elo para a construção do que podemos chamar de consenso simbólico. E é aí que entra a questão do imaginário discursivo como construção do inconsciente coletivo. Como nos escreve Charaudeau (2007. p. 53, tradução nossa). ${ }^{15}$

O imaginário é um modo de apreensão do mundo que nasce na mecânica das representações sociais, que [...] constrói significado sobre os objetos do mundo, os fenômenos que aí ocorrem, seres humanos e seus comportamentos, transformando a realidade em real significante.O imaginário sócio-discursivo resulta de um processo de simbolização do mundo afetivo-racional através da intersubjetividade das relações humanas e é depositado na memória coletiva.

Devemos levar em conta que o inconsciente pode ser apreendido através da linguagem, e isso dependerá da elaboração dos elementos simbólicos recebidos pelos individuos ao longo da vida e de como tais elementos são administrados.

A estrutura hierárquica é baseada e construida através da linguagem, na medida em que a palavra é um fenômeno ideológico por natureza, que carrega uma carga de valores culturais que evidenciam as diferenças de opiniões "e as contradições da sociedade, tornando-se um palco de conflitos" (BAKHTIN, 2017, p. 282).

Sabe-se que a enunciação está fortemente ligada às condições da comunicação, que, por sua vez, estão relacionadas às estruturas de natureza social (portanto, ideológica); a enunciação não existe fora de um contexto social. "A palavra é o campo onde se confrontam os valores sociais; os conflitos da língua refletem os conflitos de classe no interior mesmo da estrutura: baseada

15 Do original: L'imaginaire est un mode d'appréhension du monde qui naît dans la mécanique des représentations sociales, laquelle, on l'a dit, construit de la signification sur les objets du monde, les phénomènes qui s'y produisent, les êtres humains et leurs comportements, transformant la réalité en réel signifiant. Il résulte d'un processus de symbolisation du monde d'ordre affectivo-rationnel à travers l'intersubjectivité des relations humaines, et se dépose dans la mémoire collective. 
entre classe social e comunidade semiótica",16 afirma Bakhtin (2017, p. 233).

Tanto Bourdieu, na sociologia, quanto Bakhtin, na filosofia da linguagem, procuraram inserir a história, a ordem social e o sujeito em suas teorias. Bourdieu concentrou suas pesquisas nas estruturas das relações sociais e na elaboração da subjetividade. Bakhtin e seu círculo de pensadores, por sua vez, privilegiaram os estudos da linguagem e sua natureza sociológica, como aponta Grillo (2005).

De acordo com o Círculo bakhtiniano, a linguagem, pela sua natureza dialógica, onde um discurso sempre nasce e evolui em relação a outro, com o discurso do outro, permite a construção de sentido. Para o filósofo russo:

Na realidade, o locutor serve-se da língua para suas necessidades enunciativas concretas (para o locutor, a construção da língua está orientada no sentido da enunciação da fala). Trata-se, para ele, de utilizar as formas normativas (admitamos, por enquanto, a legitimidade destas) num dado contexto concreto. Para ele, o centro de gravidade da língua não reside na conformidade à norma da forma utilizada, mas na nova significação que essa forma adquire no contexto. O que importa não é o aspecto da forma linguística que, em qualquer caso em que esta é utilizada, permanece sempre idêntico. Não; para o locutor o que importa é aquilo que permite que a forma linguística figure num dado contexto, aquilo que a torna um signo adequado às condições de uma situação concreta dada. Para o locutor, a forma linguistica não tem importância enquanto sinal estável e sempre igual a si mesmo, mas somente enquanto signo sempre variável e flexivel. Este é o ponto de vista do locutor (VOLÓCHINOV, 2017, p. 177).

Neste contexto, partimos para o conceito bakhtiniano de dialogismo, que é estabelecido como o princípio da linguagem, segundo o qual toda produção de discursos está ligada a outros discursos, constituindo entre eles relações de sentido. O dialogismo é considerado como intrínseco à linguagem, visto que é da natureza. Este preceito procede da ideia de que todo enunciado, tomado como unidade mínima real de comunicação, é constituído por outros enunciados, relativamente visiveis.
Toda palavra comporta duas faces. Ela é determinada tanto pelo fato de que procede de alguém, como pelo fato de que se dirige para alguém. Ela constitui justamente o produto da interação do locutor e do ouvinte. Toda palavra serve de expressão em relação ao outro (BAKHTIN, 2017, p. 113)

Assim sendo, um enunciado nunca é tido como independente, mas sim um elo em uma cadeia de outros enunciados. A noção de diálogo resulta da linguagem em uso, no entendimento de que um enunciado é produzido como sendo uma contestação a outro enunciado, além de desencadear, por sua vez, outras respostas.

Os enunciados são dialógicos enquanto concretos e situados histórica e socialmente, ou seja, enquanto uso real da linguagem; e nesse âmbito, os enunciados são valorados: não veiculam um sentido linguístico simplesmente, mas evidenciam uma expressão avaliativa no próprio enunciado. É na valoração que encontramos a ideologia que sustenta o enunciado, a ideologia (visão de mundo) de uma classe social. Por exemplo: a expressão "catador de lixo" mostra uma depreciação, uma distância social entre quem nomeia e quem é nomeado; já "catador/coletor de recicláveis" mostra uma postura ideológica de respeito.

De acordo com o pensamento de Maingueneau, a enunciação aforizante implica a ideia de uma palavra viva sempre disponivel, que atualiza o "memorável": enunciando e mostrando que enuncia, ela se dá como parte de uma repetição constitutiva (MAINGUENEAU, 2010, p. 15). No que diz respeito à expressão "Fique em casa" que ganhou as redes sociais, é uma forma de enunciado "aforizante", que tem por objetivo apreender a propagação e a circulação dos textos fragmentados ou adaptados na sociedade, e assim compreender por que razão apenas alguns trechos de um texto integral circulam principalmente nas redes sociais. Esses fragmentos podem estar no começo, no final, podem ser pequenas frases, ou pontos culminantes de um texto. São enunciados curtos e frequentemente

16 BAKHTIN, Mikhail. Marxismo e filosofia da linguagem. [S. I.]: Hucitec, 2016. Disponivel em: http://hugoribeiro.com.br/biblioteca-digital/ Bakhtin-Marxismo_filosofia_linguagem.pdf. Acesso em: 27 maio 2020 
constituídos de uma frase. De acordo com o pensamento de Maingueneau, a enunciação aforizante implica a ideia de uma palavra viva sempre disponivel, que atualiza o "memorável": enunciando e mostrando que enuncia, ela se dá como parte de uma repetição constitutiva (MAINGUENEAU, 2010, p. 15).

\section{Metodologia}

Nosso objetivo com este artigo foi, em primeiro lugar, refletir sobre as estruturas de poder real e simbólico às quais devem submeter-se os trabaIhadores de baixa ou nenhuma renda, no contexto brasileiro; em segundo lugar, o papel preponderante da linguagem na construção de cada indivíduo na sua qualidade de ser social; e em terceiro lugar, a análise do enunciado aforizante "fique em casa" segundo a posição social do sujeito.Para respondermos aos objetivos desta proposta, nossa metodologia foi construida da seguinte forma: seleção do corpus; informações sobre a base teórica da pesquisa; e os mecanismos de análise. O corpus foi constituido de dois discursos.

Primeiro, discursos da escritora e poeta Carolina Maria de Jesus, extraídos de sua obra Quarto de despejo, publicada em 1965. Carolina também foi catadora na favela do Canindé, na década de 1950, na cidade de São Paulo. Com base nos trechos de livro citado, mencionaremos: a) a designação "catadora de papel" em contraste com a denominação comumente usada "catadora de lixo"; e b) o trecho em que Carolina Maria relata como se sente quando sai da favela para catar papel nas ruas da cidade de São Paulo; e ainda c) a impossibilidade de ficar em casa e cuidar dos filhos, tendo que sair para trabalhar e trazer o sustento para casa.

Segundo, discurso de Anne Caroline, cuja entrevista foi realizada via live da rede social Instagram, do dia 3 de dezembro de 2020. Anne é designer gráfico e catadora, moradora da favela do Zaki Narchi, na cidade de São Paulo. Nessa entrevista, Anne relata a) a importância da ressignificação da palavra lixo substituída por reciclável; b) menciona o mal-estar e o preconceito de que sofrem os catadores na sociedade por serem, segundo ela, considerados como mendigos; e por fim c) o sentido dado a partir da fala de Anne Caroline ao enunciado "Fique em casa".

Os discursos da escritora e poeta Carolina Maria de Jesus, escritos na década de 1950 e o de Anne Caroline na época atual foram escolhidos pela pertinência de seus relatos do ponto de vista social e para que possamos observar quais as mudanças, contrastes e similaridades entre o discurso de uma e outra, levando em conta a variante do tempo, setenta anos as separam. Dentro deste contexto das vozes invisibilizadas, mencionaremos a questão da influência nefasta da discriminação racial como mais um agravante enfrentado pela(o)s profissionais negra(o)s do dominio da reciclagem.

No que tange ao referencial teórico sobre o qual este texto foi fundamentado, consideramos que as teorias propostas por Pierre Bourdieu sobre a estrutura de poder simbólico podem guiar a reflexão sobre como é sistematizada a sociedade brasileira e como se constroem os discursos intolerantes e discriminatórios que marginalizam os trabalhadores informais. Não menos importante para este artigo são as noções do Circulo de Mikhail Bakhtin pela sua concepção do discurso como materialidade viva, tanto histórica, cultural e social. E, por fim, devido à importância e a intensificação da linguagem digital e dos discursos proferidos nas redes sociais, sobretudo dentro da conjuntura pandêmica, não poderíamos deixar de lado a questão dos enunciados aforizantes (como vimos, noção teorizada por Dominique Maingueneau), que neste caso foi \#fiqueemcasa, além de necessário enquanto medida de prevenção contra a crise sanitária da COVID-19, o enunciado também evidenciou a questão da fratura social, sobre a situação de quem pode ou não ficar em casa.

O critério foi o de aplicar, como base desta reflexão, a teoria bourdiesiana do poder simbólico e do habitus, em diálogo com as teorias de Bakhtin, sobretudo no que diz respeito ao dialogismo (palavra como construção dialógica), a valoração e a luta pela designação na construção e produção do sentido. Quanto ao enunciado 
aforizante "fique em casa" seguiremos a linha proposta por Maingueneau.

\section{Análises discursivas}

Conforme o pensamento de Volóchinov (2017), toda palavra é um pequeno palco em que as ênfases sociais multidirecionadas se confrontam e entram em oposição. Uma palavra pronunciada, mesmo que por um único individuo, é o resultado da interação viva das forças sociais.

A noção bakhtiniana de signo ideológico, que possui um significado e remete a algo que se situa fora de si mesmo, quando aplicado ao enunciado aforizante "fique em casa", evoca-nos esta relação de alteridade, de maneira dialética. Para Bakhtin (2017), a enunciação possui uma gênese social, assim como os procedimentos dialógicos que estabelecem o conjunto da cadeia verbal. Por essas razões é que, para Bakhtin, o enunciado é percebido como o resultado da interação entre sujeitos organizados socialmente. Para ele, em cada periodo da história, os enunciados são construidos a partir de determinados valores, que se entrecruzam e se enriquecem com outros sentidos, à medida que o curso da história absorve outras projeções. Em cada época, em cada campo de atividade e em cada circulo social, os enunciados são construídos e reconstruídos à medida que valores são ressignificados. Essa ressignificação não apenas opera no curso da projeção sócio-histórico-cultural, mas, essencialmente, na interação contínua com os enunciados do outro.

Coloquemos, então, em diálogo os relatos que trazemos para esta reflexão: os discursos da escritora Carolina Maria de Jesus (1914-1977), escritos na década de 1950, em contraste com os discursos atuais da designer gráfico Anne Caroline, catadora de recicláveis, moradora da Favela do Zaki Narchi, no bairro do Carandiru, em São Paulo.

Carolina Maria de Jesus foi catadora de papel na antiga Favela do Canindé, às margens do Rio Tietê, morou em um barraco construido com latas, madeira, pedaços de telha e outros materiais que recolhia na rua. Os trechos que analisaremos para este trabalho figuram, como dissemos, no livro Quarto de despejo; esaa obra situa-se na fenda entre dois hemisférios: o dos abastados e da sobrevivência no universo árduo da favela, o uso do português formal e do português falado na favela.

Carolina apresentava um elemento hibrido na estrutura em sua escrita, isso porque ela estava situada entre dois grupos culturais e semânticos, fundamentados em duas formas de expressão: a norma culta da língua portuguesa e a influência linguística da fala informal mais utilizada na favela daquela época. De acordo com o pensamento de Bakhtin (1993), o hibridismo é um conceito da biologia que foi apropriado pela linguistica e consiste no encontro e na mistura de duas linguagens sociais diferentes, dentro de um mesmo enunciado.

O uso da língua funciona como instrumento de valorização social, e a maneira como ela é exercida atua como forma de poder simbólico ou real (BOURDIEU, 1982).

Quanto à Anne Caroline, trabalha principalmente como catadora de recicláveis, além disso, ela é universitária, tem 28 anos, formou-se em design gráfico e vislumbra uma carreira como jornalista. Anne faz uso de sua habilidade com a linguagem digital e das redes sociais para dar voz aos profissionais da reciclagem. Em suas redes sociais ela denominou-se "Bloguerinha da reciclagem".

Vejamos alguns pontos de convergência e/ou divergência entre os discursos das duas catadoras, separadas por 70 anos, ambas moradoras da cidade de São Paulo.

\subsection{Alteridade dialógica entre Lixo e Reciclagem}

a) Carolina Maria de Jesus se denominava catadora de "papel", mas era comumente chamada, inclusive pela imprensa, de catadora de "lixo", ou "lixeira", termos que ainda são usados atualmente para denominar os trabalhadores da área de recicláveis.

b) Já no caso de Anne Caroline, ela denomina-se como catadora de "recicláveis", e lamenta o uso da expressão "catador de lixo", designação que liga toda a categoria de profissionais da reciclagem com o lixo.

Sobre a atividade de catar, Carolina fazia referência como "catadora de papel", em um dos 
trechos de livro, relata: "Eu cato papel, mas não gosto. Então penso: Faz de conta que estou sonhando" (JESUS, 2019, p. 29).

A alteridade dialógica entre os termos lixo e reciclável opõe os discursos que colocam os catadores em uma posição inferiorizada, no mesmo nivel do "lixo", e as vozes que os reconhecem como profissionais da reciclagem.

Conforme o pensamento de Bakhtin, os nomes que designam alguma coisa já vêm com valoração. Na realidade, a luta dá-se pelo nome das coisas do mundo, na medida em que ao nomear algo, nós estamos valorando esse discurso.

A importância da designação que é dada pelo conjunto da sociedade a estes trabalhadores os coloca no mesmo nível semântico da sujeira. Segundo o relato de Anne Caroline (2020):

[...] referem-se ao nosso trabalho como catadores de lixo, isto equivale dizer que também fazemos 'parte' do lixo. Ao passo que quando somos reconhecidos como profissionais da reciclagem ocupamos o lugar daqueles que contribuem para a preservação da natureza. ${ }^{17}$

A expressão "acham que fazemos parte do lixo", proferida por Anne, dialoga com outros discursos que constroem estereótipos, nos quais os catadores estariam incluídos no mesmo espaço semântico da sujeira. Nesta mesma sequência discursiva, percebe-se que o enunciado relaciona-se com vozes que pressupõem a marginalização e exclusão destes trabalhadores de maneira "normativa". Da mesma forma, o enunciado infere um posicionamento austero de uma parcela da sociedade que despreza cidadãos que executam tarefas consideradas, por eles, como sendo inferiores na escala social. Isso é corroborado por Bourdieu (1996), ao afirmar que as relações de comunicação são vínculos de poder baseados em um arbítrio, em relações de violência simbólica, socialmente instituidas. Ademais, todo ato de fala só pode ser colocado em movimento por intermédio de uma experiência pessoal e coletiva que mobiliza as disposições incorporadas pelos agentes durante sua trajetória social (noção que Bourdieu cunhou de habitus).

A ideologia de uma palavra será percebida de formas distintas, a partir de um círculo social e outro. Dentro desta perspectiva, a palavra torna-se um indicador de transformações sociais.

Quando alguém formula tais enunciados, como "Acham que fazemos parte do lixo", 18 fica claro que não se trata somente da descrição de elementos da realidade, mas sim da associação ao imaginário coletivo, que o valora como uma afirmação pejorativa. Nesse enunciado, há um tom depreciativo, impregnado de vozes sociais, reconhecidas pela sociedade, que justifica um suposto elo do "outro" (o catador(a)) com a o lixo descartado. Esses discursos com apreciação negativa dialogam, muitas vezes, com outros insultantes e muitas vezes sarcásticos, estabelecendo relações de sentidos entre os diferentes enunciados.

\subsection{Preconceito cotidiano}

De forma geral, é fato que a convivência entre os sujeitos é carregada de conflitos, devido à forte relação de dominação que, para Bourdieu (1982), refere-se à relação entre individuos que ocupam diferentes posições na esfera social: os dominantes e os dominados.

O poder das palavras na circulação dos discursos com relação a trabalhadores informais (e por isso, precários), classificados negativamente, vai naturalizando avaliações cristalizadas, preconceituosas e estereotipadas.

Os catadores enfrentam desafios desde a época de Carolina Maria de Jesus (1950) até a de Anne Caroline (2020). De lá para cá, muitas coisas mudaram, as relações interpessoais tornam-se cada vez mais virtuais com a intensificação do uso da internet, neste contexto pandêmico, onde quem não dispõe de uma conexão internet e de contas nas mais diversas redes sociais tem mais dificuldades nas interações.

Carolina Maria descreveu as agruras de morar em uma favela sem recursos, onde the era ne-

\footnotetext{
17 Depoimento da Anne Caroline Nascimento concedido a pesquisadora Liz Feré em live na rede social: Instagram, na cidade São Paulo SP. Brasil, no dia 3 de novembro 2020

18 Relato de Anne Caroline, 28 anos, entrevistada para esta pesquisa em 3 de dezembro de 2020, via rede social Instagram.
} 
gada a dignidade. Tornou-se escritora e poeta discorrendo sobre as duras condições enfrentadas no seu trabalho de catadora e a sua vida na favela, a qual ela descreve como sendo "o pior cortiço que existe" acrescentando: "Eu classifico São Paulo assim: O Palácio é a sala de visita. A prefeitura é a sala de jantar e a cidade é o jardim. E a favela é quintal onde jogam os lixos" (JESUS, 2019, p. 33).

[...] Nós os pobres, viemos para as margens do rio. As margens do rio são os lugares do lixo e dos marginais. Gente da favela é considerado marginais. Não mais se vê os corvos voando as margens do rio perto dos lixos. Os homens desempregados substituiram os corvos (JESUS, 2019, p. 54).

Ao referir-se "nós os pobres", Carolina evocou a questão da designação ideológica e do pertencimento. Percebe-se a presença de outros discursos na construção deste discurso, evidenciando as relações dialógicas, em que, na voz destes outros (da classe média, dos privilegiados...) as pessoas que habitam as favelas são consideradas marginais. No segmento "os homens desempregados substituiram os corvos", ainda que em tom poético, fica clara a realidade da favela, implícita as lógicas de poder que são hierarquizadas.

Para Anne, o contexto não é muito diferente daquela época. Os utensílios apenas foram modernizados, mas a mentalidade da sociedade em relação a estes trabalhadores não mudou. Anne e Lucas (seu marido) conseguiram adquirir sua carroça, mas ela conta a grande dificuldade que têm de deslocarem-se com ela. Sobre essa questão, Anne Caroline (2020) comenta:

[...] Temos um grande problema no trânsito, as pessoas não aceitam as carroças. Nós andamos na ciclovia para evitar isso, mas acontece muito de motoristas pararem para nos agredir verbalmente, dizendo: "catador tinha que morrer, vocês não têm profissão, vagabundos". Na pior das hipóteses as agressões podem ser até mesmo físicas.

Nesse enunciado, Anne fala na primeira pessoa do plural, deixando claro uma forma de consciência de grupo, não fala por ela própria. "As pessoas não aceitam as carroças", o que significa uma afirmação generalizada, apresentada como uma ideia universalizada, uma voz até impositiva em termos de entonação.

Há certa aceitação/resignação quando diz que andam na ciclovia para evitar as agressões, porém sem efeito. As agressões verbais são expressas em modo direto, ou seja, Anne dá voz ao "outro" no seu próprio discurso, como se falasse por meio dela. Tem-se um sentido de afastamento de Anne com relação a essas vozes agressoras: «são eles que nos agridem dessa maneira».

No que diz respeito à "nova" conjuntura digital, ela não inclui (ou muito pouco) os trabalhadores informais de baixa renda, principalmente os excluidos em situação de rua, ${ }^{19}$ uma vez que "morar" na rua, não significa não trabalhar. Uma grande parte dos catadores, sobretudo das grandes cidades, moram na rua.

Antes da pandemia, Anne arrecadava uma renda satisfatória com a reciclagem de materiais recolhidos de lojas e de alguns comércios, a qual proporcionou recursos para conectar-se à internet e manter-se ativa. Anne cata com seu marido e juntos estão inscritos em um aplicativo ${ }^{20}$ de associações ${ }^{21}$ de reciclagem que os ajuda a mediar os clientes e os catadores. Mas Anne reconhece que a cor da pele os ajuda muito, ambos são brancos. E lamenta que suas/seus colegas negra(o)s não tenham as mesmas (mesmo que escassas) oportunidades. Ela conta que a(o)s colegas negra(o)s não eram (ou muito pouco) solicitados pelos clientes através do aplicativo, ao passo que Anne e seu marido conseguiam algumas oportunidades de trabalho, mesmo que

\footnotetext{
19 Mais informações sobre dados relativos a pessoas sem teto nas ruas da cidade de São Paulo disponíveis em: https://www1.folha uol.com.br/poder/2020/10/alta-de-moradores-de-rua-apos-pandemia-exigira-resposta-de-prefeito-de-sp-em-diversas-areas.shtml. 20 Disponível em: https://www.cataki.org/pt. Acesso em: 30 nov. 2020

21 No Brasil, existem 800.000 catadores. No Cataki, apenas 1400 estão cadastrados. Fonte: Associação de catadores Cataki. Disponível em: https://www.cataki.org/pt. Acesso em: Acesso em: 30 nov. 2020; e a Associação: Pimp my carroça é um movimento que atua desde 2012 para tirar os catadores de materiais recicláveis da invisibilidade - e aumentar sua renda. Disponivel em: https://pimpmycarroca.com. Acesso em: 30 nov. 2020
} 
insuficientes devido à situação pandêmica. Dos tempos longínquos que separam Anne (2020) de Carolina (1950), algumas variáveis continuam imutáveis, uma delas é esta, que serve de base estrutural à sociedade brasileira, a da discriminação baseada no preconceito racial. A discriminação direta que sofrem os catadores, motivada pela condição racial e fundamentada no preconceito, traduz-se pela preferência por catadores brancos, por "suscitarem a confiança" dos clientes, em detrimento de catadora(o)s negra(o)s.

\section{3 \#fiqueemcasa e a sociedade brasileira}

"Fique em casa" é uma forma de enunciado "aforizante", que tem por objetivo sintetizar a propagação e a circulação dos textos fragmentados ou adaptados na sociedade, e assim compreender por que razão apenas alguns trechos de um texto integral circulam principalmente nas redes sociais. Trata-se de enunciados curtos e frequentemente constituídos de uma frase. De acordo com o pensamento de Maingueneau, a enunciação aforizante implica a ideia de uma palavra viva sempre disponivel, que atualiza o "memorável": enunciando e mostrando que enuncia, ela se dá como parte de uma repetição constitutiva (MAINGUENEAU, 2010, p. 15).

Na perspectiva de Bakhtin, para quem só há fala na esfera do texto e no gênero do discurso, um enunciado feito de uma única frase (um axioma, por exemplo) constitui uma espécie de discurso fundamental. O enunciado é a unidade mínima do discurso. O enunciado é percebido quando se pode responder a ele. Enquanto não pudermos responder a um conjunto de palavras, não temos ainda um enunciado. Ao lado das declarações sentenciosas, há uma série de declarações atribuídas a um indivíduo identificado e que foram separadas de textos. Assim como diversas "frases pequenas", como "fique em casa" que circulam no espaço público têm efeito de ditos isolados e não como partes de textos.

Assim como Carolina Maria, Anne também gostaria de ficar um pouco mais em casa, no entanto, precisa sair todas as manhãs, por volta das 5 horas, para catar recicláveis e só retorna depois das 22 horas.

No caso de Carolina Maria, seu barraco foi construido com materiais que conseguiu catar, mas assim como Anne Caroline, precisava sair para trazer o sustento para seus filhos. Carolina representou a voz de tantas pessoas que faziam (e fazem) parte destas camadas historicamente sem meios de expressão. Estas camadas são formadas, em grande parte por mulheres negras, que, sozinhas, são responsáveis pelas despesas do lar.

O que as duas catadoras têm em comum é, sobretudo, a dificuldade para ter um lugar para morar e conseguir alimentar suas familias.

A realidade relatada por Carolina Maria data da metade do século passado, como indica este trecho:

\begin{abstract}
Em 1948, quando começaram a demolir as casas térreas para construir os edificios, nós, os pobres que residiamos nas habitações coletivas, fomos despejados e ficamos residindo debaixo das pontes. É por isso que eu denomino que a favela é o quarto de despejo de uma cidade. Nós, os pobres, somos os trastes velhos (JESUS, 2019, p. 17).
\end{abstract}

Nos tempos atuais, durante o ano de 2020, Anne e seus colegas catadores tiveram que enfrentar além da crise, os efeitos nefastos causados pela pandemia, sobre essa questão, Anne (2020) relata que:

[Em 2020] Nem que a gente quisesse ficar em casa não poderia, tanto por causa do nosso sustento, tanto por que a maioria dos catadores não tem casa, moram na rua. Ficar em casa como?! Isto foi muito questionado [\#fiqueemcasa,] mas ficar como ?! A gente não tem ! Inclusive na favela onde moro um incêndio queimou nossos barracos, eu e mais de 50 familias perdemos tudo. Então, não podiamos trabalhar por que tudo estava fechado por causa da pandemia e não tínhamos onde morar por que queimou tudo. ${ }^{22}$

O enunciado "fique em casa", que ganhou as redes sociais, é sem dúvida uma referência na luta contra a contaminação do virus da COVID-19. Todavia, esses dizeres só fazem sentido para aquela(e)s que tem uma casa para ficar, um trabalho para manter suas necessidades básicas e 
a possibilidade de poder trabalhar virtualmente de casa. O problema é que esse discurso, apesar de sua coerência na conjuntura atual, não é aplicável no caso da maioria dos catadores, que a despeito de trabalharem, a maioria deles deve submeter-se à necessidade de sobreviver na rua.

\section{Considerações finais}

De acordo com o pensamento bakhtiniano, cada palavra de um enunciado nos leva para além dos seus limites linguísticos. Assim sendo, fica dificil propor uma conclusão; no entanto, procuramos trazer pontos de convergências entre as teorias de Bourdieu e as do Círculo de Bakhtin, as quais acreditamos serem pertinentes no debate sobre a condição dos trabalhadores de recicláveis, em tempos de pandemia.

Consideramos também que uma reflexão quanto às condições de produção discursiva sobre o tema destes trabalhadores se faz necessária, sobretudo em um momento, como este, de anomia social. Esse conceito foi desenvolvido por Émile Durkheim (2010) e evidencia momentos comparáveis ao atual, quando a sociedade cria uma forma de interrupção das regras que regem os individuos. Com a ausência de regras, instala-se uma desordem entre estes individuos e o corpo social, fazendo com que se criem expectativas inatingiveis na estrutura da sociedade. A crise sanitária da COVID-19 intensificou o caos político, econômico e moral já existente. No que diz respeito ao caso brasileiro, essa situação gerou conflitos ainda maiores, provocando e cristalizando patologias sociais.

Lamentavelmente, a linguagem cotidiana dos brasileiros é marcada por palavras e expressões que são trazidas da época da escravidão e do coronelismo, carregadas de um peso valorativo negativo e, naturalmente, reproduzem sem cessar discursos intolerantes. Até hoje uma parcela considerável da sociedade se comporta como "seres primitivos"23 da linguagem, muitas vezes valendo-se do véu da "inconsciência".

Por fim, as palavras participam da construção do inconsciente coletivo. É através da linguagem que construimos nossas representações do mundo, bem como do lugar onde vivemos.

A dimensão do habitus bourdieusiano que pressupõe os indivíduos a apreciar determinados temas e produtos especificos que estejam em voga na alta sociedade, esta predisposição é incorporada, resultado de um trabalhado de assimilação adquirido com um certo investimento, renda e tempo. Já há algumas décadas, com a evolução no debate sobre a ecologia e a preservação da natureza, as preocupações ligadas a essas questões integraram o discurso das(os) brasileiras(os), tanto das classes abastadas quanto das mais variadas esferas da sociedade. Entretanto, estas "preocupações" não (ou muito pouco) incluem as condições indignas dos trabalhadores desfavorecidos, como é o exemplo das(os) catadoras(es)... daquelas(es), e sobretudo, daquela(e)s que sobrevivem nas ruas.

Todas as relações socializadoras são relações discursivas e o discurso aprimora as relações sociais. A grande questão é que, em um país como o Brasil, o discurso produz e reproduz preconceitos cujo alvo são sempre os mesmos cidadãos relegados às margens da sociedade. $\mathrm{E}$ é por esta razão que o enunciado "fique em casa" é um contrassenso neste contexto, na medida em que só é possivel estabelecer sentido na condição implícita de "ter uma casa para ficar", no caso contrário não há coerência.

\section{Referências}

ALMEIDA, Silvio Luiz de. Racismo estrutural. São Paulo: Pólen, 2019.

ATTALI Jacques. La voie humaine. Paris: Ed. Fayard, 2004.

BAKHTIN, Mikhail. Os gêneros do discurso. Organização, tradução, posfácio e notas de Paulo Bezerra. Notas da edição russa de Serguei Botcharov. Rio de Janeiro: Editora 34, 2016.

BAKHTIN, Mikhail. Palavra própria e palavra outra na sintaxe da enunciação. São Carlos: Pedro \& João Editores, 2011.

\footnotetext{
23 Entendemos por "seres primitivos" da linguagem, os individuos que proferem discursos insultantes ou de baixo calão, promovem discriminações e estigmas contra trabalhadores precários.
} 
BAKHTIN, Mikhail. O autor e a personagem na atividade estética. In: BAKHTIN, Mikhail. Estética da criação verbal. 4. ed. Tradução de Paulo Bezerra. São Paulo: Martins Fontes, 2003. p. 44-45.

BAKHTIN, Mikhail. (Círculo de Bakhtin) Marxismo e filosofia da linguagem: problemas fundamentais do método sociológico na ciência da linguagem (1929). Tradução de Michel Lahud, Yara Vieira. São Paulo: Hucitec, 2017.

BAKHTIN, Mikhail. Questões de literatura e estética: a teoria do romance. São Paulo: Hucitec: Ed. UNESP, 1993.

BOURDIEU, Pierre. A economia das trocas linguisticas. São Paulo: Edusp, 2008.

BOURDIEU, Pierre. Langage et pouvoir symbolique. Paris: Ed. Seuil, 2002.

BOURDIEU, Pierre. A economia das trocas lingüísticas. São Paulo: Editora da USP, 1996.

BOURDIEU, Pierre. Ce que parler veut dire. Paris: Ed. Fayard, 1982.

BOURDIEU, Pierre. Questions de sociologie. Paris: Ed. de Minuit, 1980.

CHARAUDEAU, Patrick. A conquista da opinião pública: como o discurso manipula as escolhas politicas. Tradução de Angela M. S. Corrêa. São Paulo: Contexto, 2016.

CHARAUDEAU, Patrick. Dis-moi quel est ton corpus, je te dirai quelle est ta problématique. Revue Corpus, Nice, n. 8, 2009. Disponivel em: http://www.patrick-charaudeau.com/Dis-moi-quel-est-ton-corpus-je-te.103. html. Acesso em: 30 set. 2020.

CHARAUDEAU, Patrick. Les stéréotypes, c'est bien. Les imaginaires, c'est mieux. In: BOYER, Henri. (dir.). Stéréotypage, stéréotypes: fonctionnements ordinaires et mises en scène. Paris, 2007.

CHARAUDEAU, Patrick. Uma análise semiolingüistica do texto e do discurso. In: PAULIUKONIS, Maria Aparecida Lino.; GAVAZZI, Sigrid. (org.). Da lingua ao discurso: reflexões para o ensino. Rio de Janeiro: Lucerna, 2005. p. 11-27.

DURKHEIM, Émile. Da divisão do trabalho social. São Paulo: Martins Fontes, 2007.

FAUSTO, Boris. História do Brasil. São Paulo: Editora da Universidade de São Paulo, 2007.

FERNANDEZ, Raffaella Andréa. Routes of a poetics of residues in Carolina Maria de Jesus's work. Itinerários, Araraquara, n. 27, p. 125-146, jul./dec. 2008.

FOUCAULT, Michel. Microfisica do poder. Organização e tradução de Roberto Machado. Rio de Janeiro: Edições Graal, 1979.

GIRARDI JR., Liráucio. Pierre Bourdieu: mercados linguisticos e poder simbólico. Revista Famecos, Porto Alegre, v. 24, n. 3, 2017.
GRILLO, Sheila, A noção de campo nas obras de Bourdieu e do circulo de Bakhtin : suas implicações para a teorização dos gêneros do discurso. Revista ANPOLL, Londrina, n. 19, p. 151-184, jul/dez. 2005.

GOFFMANN, Erwing. Estigma - Notas sobre a manipulação da identidade deteriorada. Rio de Janeiro: Ed. LTC, 1981.

INSTITUTO DE PESQUISA ECONÔMICA APLICADA (IPEA). Situação social das catadoras e catadores de material reciclável e reutilizável, Brasil. Disponivel em: https://www.ipea.gov.br/portal/images/stories/ PDFs/situacao_social/131219_relatorio_situacaosocial_mat_reciclavel_brasil.pdf. Acesso em: 30 nov. 2020.

JESUS, Carolina Maria de. Quarto de despejo. São Paulo: Ática, 2019.

MAINGUENEAU, Dominque. Frases sem texto. Paris: A. Colin, 2012.

MAINGUENEAU, Dominque. Aforização: enunciados sem texto? In: MAINGUENEAU, Dominque. Doze conceitos em análise do discurso. São Paulo: Parábola Editorial, 2010.

MEIRELLES, Renato; ATHAYDE, Celso. Um pais chamado favela: a maior pesquisa já feita sobre a favela brasileira. São Paulo: Gente, 2014.

SOUZA, Jessé. A ralé brasileira: quem é e como vive. Belo Horizonte: Ed. UFMG, 2016.

TAGUIEFF, Pierre-André. Dictionnaire historique et critique du racisme. Paris: Ed. PUF, 2013.

VOLÓCHINOV, Valentin (Círculo de Bakhtin). Marxismo e filosofia da linguagem. Problemas fundamentais do método sociológico na ciência da linguagem. Tradução, notas e glossário de Sheila Grillo e Ekaterina Vólkova Américo. Ensaio introdutório de Sheila Grillo. São Paulo: Ed. 34, 2017.

WEBER, Max. Économie et société. Tome 1: Les catégories de la société. Ed. Pocket, 2003.

\section{Liz Feré}

Doutora e professora em Ciências da Informação e da Comunicação; especialista em Análise do discurso e psicanálise, na Universidade Paris VIII. Pertence ao laboratório de pesquisas Centre d'Études sur les Médias, les Technologies et l'Internationalisation (CEMTI), unidade de pesquisa da Escola doutoral da mesma universidade. Membro da Associação de Discursos da América Latina (ADAL). 


\section{Endereço para correspondência}

\section{Liz Feré}

Université Paris 8

Département d'Information et communication (CEMTI)

2 Rue de la Liberté

93200 Saint-Denis

France

Os textos deste artigo foram revisados pela Poá

Comunicação e submetidos para validação da autora antes da publicação. 